\title{
Medication Safety Climate Questionnaire: Development and Psychometric Analysis
}

\author{
Kumud Kantilal $^{1}$, Vivian Auyeung ${ }^{2}$, Cate Whittlesea ${ }^{3}$ and Alice Oborne ${ }^{1}$ \\ 1. Department of Pharmacy, Guy's and St Thomas ' NHS Foundation Trust, London, SE1 9RT, UK \\ 2. Institute of Pharmaceutical Science, King's College London, London, SE1 9NH, UK \\ 3. School of Medicine, Pharmacy and Health, Durham University, Stockton-on-Tees, TS17 6BH, UK
}

Received: January 15, 2015 / Accepted: January 30, 2015 / Published: January 30, 2015.

\begin{abstract}
Medication safety improvement strategies require a better understanding of the safety culture specifically related to medicines. In healthcare, safety climate questionnaires are often used as a proxy measure of the underlying safety culture. However, there are currently not known instruments to assess medication safety climate. The study therefore aimed to develop and evaluate a medication safety climate questionnaire for healthcare staff in UK hospitals. Two validated patient safety climate instruments were adapted to develop a Medication Safety Climate (MSC) questionnaire. Data was collected from 510 healthcare professionals (response rate 9.4\%); routinely involved with prescribing, dispensing, administering and monitoring medication; in two acute NHS hospitals in London. Confirmatory factor analysis and reliability analyses were conducted to determine the psychometric properties of the MSC questionnaire. Results showed that the 50-item MSC questionnaire contained nine factors-teamwork climate, safety climate, job satisfaction, stress recognition, perceptions of management, working conditions, organisational learning, feedback and communication about error and management support for medication safety. Internal consistency reliability scores for eight of the nine factors were $>0.7$ and ranged from 0.64 to 0.9 . Correlations between eight factors showed a moderate relationship between the factors; ranging from 0.232 to 0.669 . One factor, Stress recognition, had a weak and negative correlation with all other factors. Confirmatory factor analysis achieved an almost adequate model fit $\left(\chi^{2} / \mathrm{df}\right.$ ratio 2.572 ; root mean square error of approximation (RMSEA) 0.069; comparative fit index (CFI) 0.791). The MSC questionnaire demonstrated reasonable psychometric properties. Further refinement using exploratory factor analysis is, however, required to improve the questionnaire's validity. This is the first known instrument to measure mediation safety climate in the UK and could be used to inform medication safety improvement strategies and monitor change in healthcare staff perceptions, related to medication safety, over time.
\end{abstract}

Key words: Medication safety, safety culture, safety climate, psychometrics.

\section{Introduction}

A global drive to improve patient safety, alongside increasing research into the culture of safety in healthcare, gained momentum in the early 2000s [1]. The Department of Health in England recognised that more could be done to minimise preventable harms from occurring. A report highlighted that the NHS could learn from the experience and knowledge of other sectors in two key areas-safety culture and reporting systems [2]. Recent high profile failings in the

Corresponding author: Kumud Kantilal, MRes, principal pharmacist, research field: medicines safety. E-mail: kumud.kantilal@gstt.nhs.uk.
English NHS have re-emphasised the need for a cultural transformation to improve patient safety [3, 4].

Reporting systems have a dual purpose of providing data and generating a culture of safety through raising awareness [5]. The National Reporting and Learning System (NRLS) for England and Wales was established in 2003 to collect and analyse patient safety incidents [6]. From 2005 to 2010, 526,186 medication incidents were submitted which represented the second highest (9.68\%) incident category reported to the NRLS. And over 16\% $(86,821)$ of these caused actual patient harm [7].

The terms safety culture and safety climate have 
been extensively debated by safety researchers and are often used interchangeably [8]. However, the difference between culture and climate is often reduced to a difference in methodology. Studies involving healthcare worker surveys are regarded as studies of safety climate and those that involve detailed longitudinal observations are considered studies of safety culture [9]. Because of the ease and ability to quantitatively measure safety climate, it is often used as a proxy measure of safety culture [10].

Safety climate surveys are being increasingly used in healthcare organisations and several instruments have been developed [11]. Researchers have also sought to explore the relationship between safety culture and patient outcomes. The majority of the research has been conducted in hospital settings and focused on safety climate, using cross-sectional surveys. Studies have not found any significant relationship between safety climate and patient outcomes [12] but emerging evidence suggests a connection between safety climate and specific patient outcomes [13]. Medication errors have received substantial attention in terms of healthcare related outcomes and are often viewed as one of many indices of overall care quality [14]. Studies evaluating the relationship between safety climate and medication safety are, however, inconclusive. Some studies found that a more positive safety climate was associated with fewer medication errors $[14,15]$. Whereas, others have found that an increase in the medication incident reporting rate may suggest a positive safety culture $[6,16]$.

The use of medicines is the most frequent of all health care interventions. Medication use can be viewed as a system of complex components and processes. The main processes in the medication use system are prescribing, dispensing, administration and monitoring; and each process has its own opportunities for errors. A medication safety programme therefore needs to encompass a broad array of changes in procedures, teams and training in order to improve safety across a whole system. This requires knowledge of human factors engineering, establishing an integrated well-organised strategic medication safety plan and creating a culture of safety [17]. A better understanding of the safety culture specifically related to medicines is therefore crucial.

To date, there have been no studies exploring the medication safety climate of healthcare professionals. Medication safety climate (MSC) can be regarded as the healthcare workers perceptions of practices, policies, procedures and routines about medication safety in their work environment at a given point in time, where medication safety is defined as the "activities to avoid, prevent or correct adverse drug events which may result from the use of medicines" (p. 195) [17]. The purpose of the study was to develop a MSC questionnaire from extant patient safety climate questionnaires; and to demonstrate the psychometric properties of the newly developed questionnaire. Hypotheses to check the questionnaire's reliability and validity were that the MSC questionnaire will show good internal consistency (hypothesis 1); the scores for the factors that make up the MSC questionnaire will be moderately correlated (hypothesis 2); and that the data in the study will fit the a priori factor structure model of the MSC questionnaire (hypothesis 3).

\section{Methods}

\subsection{Design, Setting and Sample}

A cross-sectional design was used. Two acute hospitals from one NHS Foundation Trust in London were included in the study. Healthcare professionals that were routinely involved with prescribing, dispensing, administering or monitoring medication as part of their clinical roles were invited to participate. The whole population $(n=5,422)$ of doctors, dentists, nurses, midwives, operating department practitioners (ODPs), pharmacists and pharmacy technicians that had been directly employed by the Trust for at least three months were included in the study. Agency and bank healthcare workers employed by external contractors, employees working in the Trust for less 
than three months, allied health professionals and non-clinical staff were excluded. The focus of the current study was to demonstrate the psychometric properties of the newly developed questionnaire; therefore 300 respondents were required for the factor analysis. The sample size needed to conduct a factor analysis is much debated by the experts in the area and therefore numerous rules-of-thumb exist [18]. Sample sizes between 100 and 300 are recommended for factor analysis [19]. A low response rate was anticipated [20] therefore the survey was open to the entire population of eligible clinical staff.

\subsection{Instrument Selection, Adaptation and Administration}

A review of patient safety climate instruments used in the UK healthcare setting identified two questionnaires suitable for adaptation, the Safety Attitudes Questionnaire (SAQ) [21] and the Agency for Healthcare Research and Quality (AHRQ) Hospital Survey on Patient Safety Culture (HSOPSC) [22]. Both questionnaires have been developed in the USA; but used extensively and have proven reliability and validity information [23]. Both the SAQ and HSOPSC have been translated into many languages and are used globally [24, 25]. The SAQ (Short Form) is a 41-item questionnaire, comprised of six factors-Teamwork climate, Safety climate, Job satisfaction, Stress recognition, Perceptions of management (at the clinical area and hospital levels) and Working conditions. Although the SAQ included key concepts important for medication safety, other concepts, such as error reporting, learning from errors and the influence of leadership on medication safety were missing [5]. Three factors (containing nine items) from the HSOPSC; Organisational learning -continuous learning, Feedback and communication about error and Management support for patient safety; were therefore considered appropriate for adaptation in the study.

All SAQ items and the nine items from the
HSOPSC were reviewed and adapted in the context of medication safety. Changes to the wording were minimised, however, terminology was changed to reflect those used in the UK, e.g., physician was changed to doctor, personnel was changed to clinical staff and fatigued was amended to tired. A 5-point Likert response scale of agreement (Disagree strongly, Disagree slightly, Neutral/Neither agree nor disagree, Agree slightly, Agree strongly) as used in the SAQ and HSOPSC were adopted for the current study. The SAQ also included a 'Not applicable' option, which was adopted. In addition, a 'Don't know' response option was added, as requested by the expert panel. The final 50-item MSC questionnaire, containing nine factors, was converted to a web-format. The web-survey included questions about the participant age, gender, profession, professional grade, the number of years they were employed in the Trust and questions about their work site (e.g. clinical area or department where they spend most of their working week). In addition, two open-ended questions were included for participants to comment on their top three recommendations and current concerns about medication safety. The survey was piloted for two weeks before administration at the two study sites.

A link to the web-survey was emailed to eligible clinical staff using group work email addresses from a list compiled by the co-chair of the Medicine Safety Committee. The survey was open for a total of six weeks (16 June to 27 July 2014). Email reminders were sent two and four weeks after the invitation email.

\subsection{Data Analysis}

Descriptive statistics were computed for the sample and each of the factors for the climate questionnaire. In questionnaire research, reliability refers to participants giving consistent responses because they interpret and understand the questions in a similar manner [26]. To examine hypothesis 1, internal consistency reliability was assessed using Cronbach's 
$\alpha$ coefficient, as it is the only reliability index that can be performed with one test administration [27]. Cronbach's $\alpha$ coefficient values should ideally be above 0.7 [27] but values $\geq 0.6$ are also acceptable [22].

To test hypothesis 2 , the inter-correlations between the composite scores of the nine factors were checked using Pearson's correlation (r). Moderate correlations $(\mathrm{r}=0.2-0.4)$ [22] demonstrate discriminant validity, indicating that the factors measure distinct constructs.

Confirmatory factor analysis (CFA) was used to explore whether the study data fit the a priori nine-factor model (hypothesis 3). Factor analysis is a statistical procedure to investigate inter-correlations between observed and latent variables. The current study involved the development of a medication safety climate scale from two validated questionnaires; therefore CFA was employed to test the goodness of fit of the hypothesised factor model to the data. Confirmatory factor analysis was carried out on IBM SPSS Amos using the maximum likelihood estimation [28]. The model chi-squared $\left(\chi^{2}\right), \chi^{2} /$ degrees of freedom (df) ratio, comparative fit index (CFI) and root mean square error of approximation (RMSEA) were used to evaluate model fit. Acceptable model fit is evidenced by a non-significant $\chi^{2}(P>0.05)$ [28]; $\chi^{2} /$ df ratio 2-5 [29]; CFI $>0.9$ [30] and RMSEA < 0.07 [31]. Standardised factor loadings for individual items were also examined. Items with high factor loadings $(>0.6)$ are recommended as they indicate that the item is aligned with the factor [32].

Statistical significance was defined as $P \leq 0.05$. Statistical analyses were performed using IBM SPSS Statistics (v. 21), for the descriptive statistics, reliability and inter-corrections, and IBM SPSS Amos (v. 22) for CFA and goodness of fit indices.

\section{Results}

\subsection{Respondents}

The overall response rate was $9.4 \%(510 / 5,422)$. The analysable sample size was 328 , after the data was cleaned (Fig. 1). Nurses and midwives jointly accounted for a third of the participants $(34.8 \%)$; followed by doctors and dentists who also accounted for just under a third of participants (32.3\%) and pharmacy staff represented $17.9 \%$ of participants. No responses were received from ODPs. Two-thirds of respondents worked mainly at one of the acute hospital sites. More experienced doctors and dentists completed the questionnaire; $21.6 \%$ of Consultants or Associate specialists compared to $3.4 \%$ of junior doctors. Half of the respondents were between 30 to 49 years old and majority (62.2\%) had been working in the trust for three years or more. A detailed breakdown of respondent characteristics is shown in Table 1.

\subsection{Confirmatory Factor Analysis}

Confirmatory factor analysis of the nine factor model structure indicated an almost adequate fit of the model to the data $\left(\chi^{2}=2337.937, \mathrm{df}=909, P<0.001\right.$, $\mathrm{n}=328)$. The significant $P$ value suggested that the model was not consistent with the data. The $\chi^{2} / \mathrm{df}$ ratio of 2.572 suggested an adequate model fit. The RMSEA value of 0.069 (90\% CI $0.066-0.073, P<$ 0.001 ) indicated acceptable fit. The CFI result of 0.791 was indicative of a poor fit of the model to the data. The standardized factor loadings ranged from 0.27

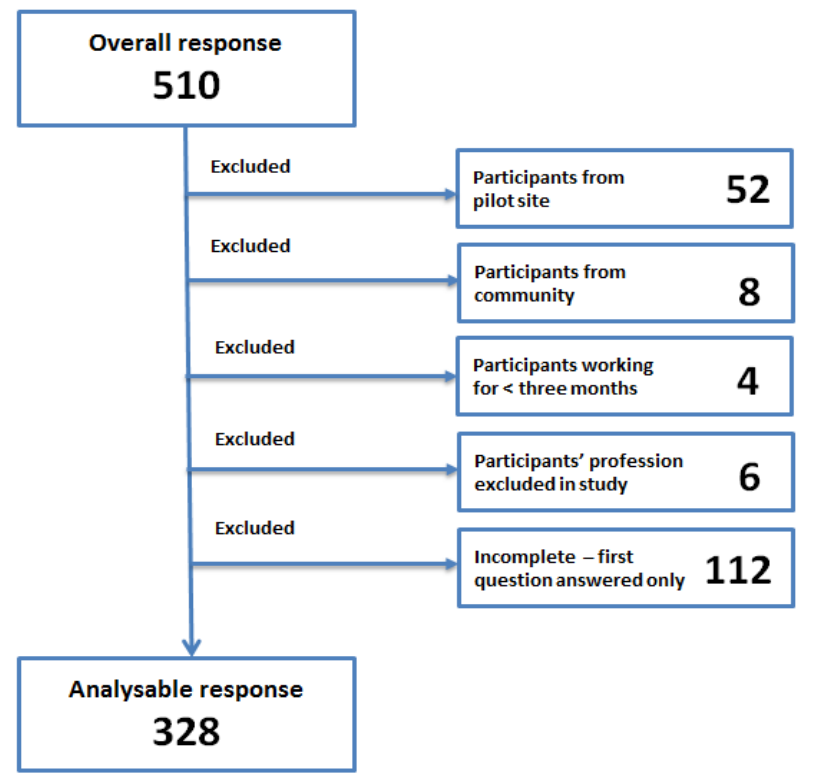

Fig. 1 Excluded respondent numbers and reasons. 
Table 1 Respondent characteristics.

\begin{tabular}{|c|c|c|c|}
\hline \multirow{2}{*}{ Characteristic } & & \multicolumn{2}{|c|}{ Total $(n=328)$} \\
\hline & & $\mathrm{n}$ & $\%$ \\
\hline \multirow{3}{*}{ Gender } & Male & 76 & $(23.2)$ \\
\hline & Female & 203 & $(61.9)$ \\
\hline & Missing & 49 & $(14.9)$ \\
\hline \multirow{7}{*}{ Professional group } & Doctor & 97 & $(29.6)$ \\
\hline & Dentist & 9 & $(2.7)$ \\
\hline & Nurse & 94 & $(28.7)$ \\
\hline & Midwife & 20 & $(6.1)$ \\
\hline & Pharmacist & 51 & $(15.5)$ \\
\hline & Pharmacy technician & 8 & $(2.4)$ \\
\hline & Missing & 49 & $(14.9)$ \\
\hline \multirow{9}{*}{ Job grade or band } & Consultant or Associate specialist & 71 & $(21.6)$ \\
\hline & Clinical fellow or Registrar & 12 & $(3.7)$ \\
\hline & Specialist Trainee year 4-7 & 7 & $(2.1)$ \\
\hline & Specialist Trainee year 1-3 & 3 & $(0.9)$ \\
\hline & Foundation year 1-2 & 11 & $(3.4)$ \\
\hline & AfC band 4-6 & 74 & $(22.6)$ \\
\hline & AfC band 7 & 44 & $(13.4)$ \\
\hline & AfC band 8 & 51 & $(15.5)$ \\
\hline & Missing & 55 & $(16.8)$ \\
\hline \multirow{11}{*}{ Age in years } & Under 25 & 6 & $(1.8)$ \\
\hline & $25-29$ & 38 & $(11.6)$ \\
\hline & $30-34$ & 41 & $(12.5)$ \\
\hline & $35-39$ & 45 & $(13.7)$ \\
\hline & $40-44$ & 44 & $(13.4)$ \\
\hline & $45-49$ & 34 & $(10.4)$ \\
\hline & $50-55$ & 33 & $(10.1)$ \\
\hline & $55-59$ & 19 & $(5.8)$ \\
\hline & $60-64$ & 15 & (4.6) \\
\hline & $\geqslant 65$ & 4 & $(1.2)$ \\
\hline & Missing & 49 & (14.9) \\
\hline \multirow{6}{*}{ Duration of employment } & 3-11 months & 40 & $(12.2)$ \\
\hline & $1-2$ years & 35 & $(10.7)$ \\
\hline & $3-5$ years & 55 & $(16.8)$ \\
\hline & $6-10$ years & 50 & $(15.2)$ \\
\hline & $>10$ years & 99 & $(30.2)$ \\
\hline & Missing & 49 & $(14.9)$ \\
\hline
\end{tabular}

AfC: Agenda for change (national pay system for NHS staff except doctors and senior managers).

(Teamwork) to 0.89 (Stress recognition) and were generally large $(>0.6)$. Factor loadings for individual items of the MSC scale are shown in the supplement to this publication. Three items had low factor loadings $(<0.40)$ items A2 (Teamwork dimension), B1 (Safety climate) and E8 (Management support for medication safety).

\subsection{Internal Consistency Reliability}

Internal consistency reliability was assessed using Cronbach's $\alpha$ coefficient and ranged from 0.64 (Management support for medication safety) to 0.9 
(Perceptions of management), with an average of 0.80 (Table 2). Eight dimensions had $\alpha$ scores $>0.7$ and one dimension had a score of 0.64 , indicating good scale reliability.

\subsection{Inter-Correlation between Factors}

The correlations between composite scores for eight factors ranged from 0.232 to 0.669 (with $P<0.01$ ) showing a moderate relationship between the factors (Table 2). One of the factors, Stress Recognition had weak and negative correlations with all other factors (range from -0.086 to -0.128 ). The discriminant validity was therefore satisfactory as the majority of the factors were moderately related and one factor was weakly related.

\section{Discussion}

The reliability of the nine factors of the MSC scale was good with Cronbach's $\alpha$ scores above 0.7 , with one exception-Management support for medication safety dimension $(\alpha=0.64)$. Similar findings were obtained in some European studies [33, 34]. The internal reliability scores for this factor was high $(0.83)$ in the original USA study [22]. This may suggest that the questions for this factor are being interpreted differently by European healthcare workers.

The overall model fit was almost adequate, as evidenced by acceptable $\chi^{2} / \mathrm{df}$ ratio (2.572; ratio $2-5$ is acceptable) and acceptable RMSEA index (0.069; values $<0.07$ indicate acceptable model fit). The CFI value of 0.791 was indicative of a poor fit of the model to the data (acceptable model fit requires a CFI of $>0.9$ ). This suggests that some modification may be needed to identify a model that fits the data better.

Despite its popularity, the $\chi^{2}$ statistic has limitations. The $\chi^{2}$ is sensitive to sample size, and often rejects the model with a large sample size and may not be able to discriminate between good and poor fitting models where sample sizes are small [29]. The sample size for the current study was small and therefore the $\chi^{2}$ statistic may have lacked power to determine the model fit.

Examination of the inter-correlations between the dimensions of the MSC scale indicated that the Stress Recognition factor had weak and negative correlations with all other factors (range from -0.086 to -0.128 ). This finding is consistent with published literature [21, $35,36]$; suggesting that items in the Stress recognition factor may not contribute to the overall safety climate construct. Items comprising the Stress recognition factor assess individual attitudes or behavior and are therefore different from the other factors which focus on behaviors among people working in a clinical area.

The study has several limitations. Although the sample size was adequate to conduct the factor

Table 2 Inter-correlation, descriptive statistics and internal consistency reliability $(\alpha)$.

\begin{tabular}{|c|c|c|c|c|c|c|c|c|c|c|c|}
\hline Dimension & Mean & SD & $\alpha$ & 1 & 2 & 3 & 4 & 5 & 6 & 7 & 8 \\
\hline 1. Teamwork & 4.60 & 0.55 & 0.79 & - & & & & & & & \\
\hline 2. Safety Climate & 4.47 & 0.52 & 0.76 & $0.669^{* *}$ & - & & & & & & \\
\hline 3. Job Satisfaction & 4.36 & 0.69 & 0.86 & $0.416^{* *}$ & $0.451^{* *}$ & - & & & & & \\
\hline 4. Stress Recognition & 3.67 & 1.11 & 0.85 & $-0.128^{*}$ & -0.108 & -0.105 & - & & & & \\
\hline 5. Perceptions of Management & 3.97 & 0.72 & 0.90 & $0.361^{* *}$ & $0.426^{* *}$ & $0.561^{* *}$ & -0.086 & - & & & \\
\hline 6. Working Conditions & 4.28 & 0.79 & 0.80 & $0.374^{* *}$ & $0.417^{* *}$ & $0.484^{* *}$ & $-0.159^{*}$ & $0.516^{* *}$ & - & & \\
\hline $\begin{array}{l}\text { 7. Organisational } \\
\text { learning-continuous learning }\end{array}$ & 4.38 & 0.68 & 0.79 & $0.536^{* *}$ & $0.671^{* *}$ & $0.247^{* *}$ & -0.099 & $0.329^{* *}$ & $0.283^{* *}$ & - & \\
\hline $\begin{array}{l}\text { 8. Feedback \& communication } \\
\text { about error }\end{array}$ & 4.21 & 0.86 & 0.84 & $0.353^{* *}$ & $0.593^{* *}$ & $0.247^{* *}$ & $-0.124^{*}$ & $0.330^{* *}$ & $0.289^{* *}$ & $0.463^{* *}$ & - \\
\hline $\begin{array}{l}\text { 9. Management support for } \\
\text { medication safety }\end{array}$ & 3.72 & 0.85 & 0.64 & $0.295^{* *}$ & $0.370^{* *}$ & $0.389^{* *}$ & -0.104 & $0.625^{* *}$ & $0.336^{* *}$ & $0.232^{* *}$ & $0.356^{* *}$ \\
\hline
\end{tabular}
medication safety

${ }^{*} P<0.0105$ 
analysis, the low response rate cannot rule out selection bias. Therefore, generalisation of the findings to other UK hospitals is limited. Nonetheless, the sample consisted of multidisciplinary healthcare workers routinely involved with the use of medicines in hospitals. Analysis at the clinical area or department level was not possible as varying free-text responses were received. This would have been valuable, given that more variability occurs between clinical areas than within clinical areas. Consequently, it has been suggested that improvement strategies targeted at the clinical area level would be easier than hospital wide [21]. The MSC questionnaire items were modifications of items from two existing patient safety climate questionnaires, therefore caution should be exercised when comparing results of the current study to those of the original factor analysis.

The study did not examine the association between medication safety climate and objective measures of medication safety such as medication incidents. This could have been used to test the predictive validity of the MSC questionnaire.

\section{Conclusions}

The MSC questionnaire demonstrated reasonable psychometric properties; it has good reliability and almost adequate validity. Exploratory factor analysis is therefore recommended to further refine the items. The current study used a quantitative approach and therefore addressed what the medication safety climate at one hospital trust was. To explore why the medication safety culture within the trust is the way it is, qualitative methods such as ethnography or observations and interviews would be more suitable. Future research could also focus on assessing the relationship between medication safety climate and objective measures of medication safety outcomes such as medication incidents. This will be important to establish the criterion validity of the questionnaire. The questionnaire has great potential for use in healthcare if the scores could additionally demonstrate a link to objective measures of medication safety improvements, thus validating that it can measure change.

\section{Acknowledgements}

The authors would like to thank the staff at the two hospitals for completing the survey; and T. Murrells, for his statistical input.

\section{Funding}

Kumud Kantilal was supported by the National Institute for Health Research (NIHR) Biomedical Research Centre based at Guy's and St Thomas' NHS Foundation Trust and King's College London. The views expressed are those of the authors and not necessarily those of the NHS, the NIHR or the Department of Health.

\section{References}

[1] Institute of Medicine. 2000. To Err Is Human: Building a Safer Health System. Washington DC: The National Academies Press.

[2] Department of Health. 2000. An Organisation with a Memory: a Report of an Expert Group on Learning from Adverse Events in the NHS. London: TSO.

[3] Department of Health. 2013. A Promise to Learn-a Commitment to Act: Improving the Safety of Patients in England. London: TSO.

[4] Francis, R. 2013. Report of the Mid Staffordshire NHS Foundation Trust Public Inquiry. London (HC 947): TSO.

[5] Vincent, C. 2011. "Essentials of Patient Safety." Accessed August 22, 2014. http://www1.imperial.ac.uk/cpssq/cpssq_publications/.

[6] Hutchinson, A., Young, T., and Cooper, K. 2009. "Trends in Healthcare Incident Reporting and Relationship to Safety and Quality Data in Acute Hospitals: Results From the National Reporting and Learning System." Qual. Saf. Health Care 18 (1): 5-10.

[7] Cousins, D. H., Gerrett, D., and Warner, B. 2012. "A Review of Medication Incidents Reported to the National Reporting and Learning System in England and Wales over 6 Years (2005-2010).” B. J. Clin. Pharmacol. 74 (4): 597-604.

[8] Cox, S., and Flin, R. 1998. "Safety Culture: Philosopher's Stone or Man of Straw? ” Work Stress 12 (3): 189-201.

[9] Weaver, S. J., Lubomksi, L. H., and Wilson, R. F. 2013. 
"Promoting a Culture of Safety as a Patient Safety Strategy a Systematic Review." Ann. Intern. Medicine 158 (5_Part_2): 369-74.

[10] Morello, R. T., Lowthian, J. A., and Barker, A. L. 2013. "Strategies for Improving Patient Safety Culture in Hospitals: a Systematic Review." BMJ Qual. Saf. 22 (1): 11-8.

[11] Flin, R., Burns, C., and Mearns, K. 2006. "Measuring Safety Climate in Health Care." Qual. Saf. Health Care 15 (2): 109-15.

[12] Groves, P. S. 2014. "The Relationship Between Safety Culture and Patient Outcomes Results from Pilot Meta-Analyses.” West J. Nurs. Res. 36 (1): 66-83.

[13] DiCuccio, M. H. 2014. "The Relationship Between Patient Safety Culture and Patient Outcomes: A Systematic Review." J. Patient Saf. doi:10.1097/PTS.0000000000000058.

[14] Hofmann, D. A., and Mark, B. 2006. "An Investigation of the Relationship Between Safety Climate and Medication Errors as Well as Other Nurse and Patient Outcomes." Person. Psychol. 59 (4): 847-69.

[15] Otero, P., Leyton, A., and Mariani, G. 2008. "Medication Errors in Pediatric Inpatients: Prevalence and Results of a Prevention Program.” Pediatrics 122 (3): e737-e743.

[16] Abstoss, K. M., Shaw, B. E., and Owens, T. A. 2011. "Increasing Medication Error Reporting Rates While Reducing Harm Through Simultaneous Cultural and System-level Interventions in an Intensive Care Unit." BMJ Qual. Saf. 20 (11): 914-22.

[17] Council of Europe. 2006. "Creation of a better medication safety culture in Europe: building up safe medication practices." Acceesed December 13, 2013. http://www.coe.int/t/e/social_cohesion/soc-sp/medication $\% 20$ safety $\% 20$ culture $\% 20$ report $\% 20$ e.

[18] Terwee, C. B., Bot, S. D., and de Boer, M. R. 2007. "Quality Criteria Were Proposed for Measurement Properties of Health Status Questionnaires." J. Clin. Epidemiol. 60 (1): 34-42.

[19] Pett, M., Lackey, N., and Sullivan, J. 2003. Making Sense of Factor Analysis: the Use of Factor Analysis for Instrument Developement in Health Care Research. California: Sage Publications.

[20] Dykema, J., Jones, N. R., and Piche, T. 2013. "Surveying Clinicians by Web: Current Issues in Design and Administration." Evaluation \& the Health Professions 36 (3): 352-81.

[21] Sexton, J. B., Helmreich, R. L., and Neilands, T. B. 2006. "The Safety Attitudes Questionnaire: Psychometric Properties, Benchmarking Data, and Emerging Research." BMC Health Serv. Res. 6 (1): 44.

[22] Sorra, J., and Nieva, V. 2004. Hospital Survey on Patient Safety Culture. Rockville, MD: Agency for Healthcare
Research and Quality.

[23] Etchegaray, J. M., and Thomas, E. J. 2012. "Comparing Two Safety Culture Surveys: Safety Attitudes Questionnaire and Hospital Survey on Patient Safety." BMJ Qual. Saf. 21 (6): 490-98.

[24] Deilkas, E. T., and Hofoss, D. 2008. "Psychometric Properties of the Norwegian Version of the Safety Attitudes Questionnaire (SAQ), Generic version (Short Form 2006).” BMC Health Serv. Res. 8: 191.

[25] Zhu, J., Li, L., and Zhao, H. 2014. "Development of a Patient Safety Climate Survey for Chinese Hospitals: Cross-national Adaptation and Psychometric Evaluation." BMJ Qual. Saf. 23 (10): 847-56. doi:10.1136/bmjqs-2013-002664.

[26] Boynton, P. M., and Greenhalgh, T. 2004. "Selecting, Designing, and Developing Your Questionnaire." BMJ 328: 1312-5.

[27] DeVon, H. A., Block, M. E., and Moyle-Wright, P. 2007. "A Psychometric Toolbox for Testing Validity and Reliability." J. Nurs. Scholarsh. 39 (2): 155-64.

[28] Byrne, B. M. 2010. Structural Equation Modeling with AMOS: Basic Concepts, Applications and Programming, 2nd ed. London: Psychology Press.

[29] Hooper, D., Coughlan, J., and Mullen, M. 2008. "Structural Equation Modelling: Guidelines for Determining Model Fit." Electronic Journal of Business Research Methods 6 (1): 53-60.

[30] Hu, L. T., and Bentler, P. M. 1999. "Cutoff Criteria for Fit Indexes in Covariance Structure Analysis: Conventional Criteria Versus New Alternatives." Struct. Equ. Modeling 6 (1): 1-55.

[31] Steiger, J. H. 2007. "Understanding the Limitations of Global Fit Assessment in Structural Equation Modeling." Pers. Individ. Dif. 42 (5): 893-98.

[32] Ferguson, E., and Cox, T. 1993. "Exploratory Factor Analysis: A Users' Guide." International Journal of Selection and Assessment 1 (2): 84-94.

[33] Waterson, P., Griffiths, P., and Stride, C. 2010. "Psychometric Properties of the Hospital Survey on Patient Safety Culture: Findings From the UK." Qual. Saf. Health Care 19 (5): e2.

[34] Smits, M., Christiaans-Dingelhoff, I., and Wagner, C. 2008. "The Psychometric Properties of the 'Hospital Survey on Patient Safety Culture' in Dutch Hospitals." BMC Health Serv. Res. 8: 230.

[35] Speroff, T., Nwosu, S., and Greevy, R. 2010. "Organisational Culture: Variation Across Hospitals and Connection to Patient Safety Climate." Qual. Saf. Health Care 19 (6): 592-6.

[36] Taylor, J. A., and Pandian, R. 2013. "A Dissonant Scale: Stress Recognition in the SAQ." BMC Res. Notes 6 (1): 302. 


\section{Appendix A}

Table 1 Supplementary material: Standardised item factor loadings.

\begin{tabular}{|c|c|c|c|c|c|c|c|c|c|c|}
\hline \multirow{2}{*}{ Items } & & \multirow{2}{*}{$\begin{array}{l}\text { Mean } \\
\text { (5-point scale) }\end{array}$} & \multirow{2}{*}{ SD } & \multicolumn{7}{|c|}{ Factor loadings } \\
\hline & & & & TW & $\mathrm{SC}$ & JS & SR & $\mathrm{PM}$ & WC OL & FCE MS \\
\hline 1. & Teamwork (TW) & & & & & & & & & \\
\hline A1 & $\begin{array}{l}\text { Clinical staff input regarding medication safety } \\
\text { is well received in this clinical area. }\end{array}$ & 4.63 & 0.75 & 0.69 & & & & & & \\
\hline A2 (R) & $\begin{array}{l}\text { In this clinical area, it is difficult to speak up if I } \\
\text { perceive a problem with medication safety. }\end{array}$ & 4.53 & 0.96 & 0.27 & & & & & & \\
\hline A3 & $\begin{array}{l}\text { Disagreements about medication safety are } \\
\text { resolved appropriately in this clinical area (i.e. not } \\
\text { WHO is right, but WHAT is best for the patient). }\end{array}$ & 4.51 & 0.89 & 0.72 & & & & & & \\
\hline A4 & $\begin{array}{l}\text { I have the support I need from other clinical staff } \\
\text { to care for patients. }\end{array}$ & 4.64 & 0.81 & 0.66 & & & & & & \\
\hline A5 & $\begin{array}{l}\text { It is easy for staff here to ask questions about } \\
\text { medication when there is something that they do } \\
\text { not understand. }\end{array}$ & 4.64 & 0.80 & 0.75 & & & & & & \\
\hline A6 & $\begin{array}{l}\text { The clinical staff here work well together as a } \\
\text { well co-ordinated team. }\end{array}$ & 4.53 & 0.80 & 0.79 & & & & & & \\
\hline 2. & Safety Climate (SC) & & & & & & & & & \\
\hline A7 & I would feel safe being treated here as a patient. & 4.62 & 0.78 & & 0.77 & & & & & \\
\hline A8 & $\begin{array}{l}\text { I know the proper channels to direct questions } \\
\text { regarding medication safety in this clinical area. }\end{array}$ & 4.67 & 0.77 & & 0.68 & & & & & \\
\hline A9 & $\begin{array}{l}\text { I receive appropriate feedback about my } \\
\text { performance. }\end{array}$ & 4.09 & 1.12 & & 0.61 & & & & & \\
\hline A10 & $\begin{array}{l}\text { I am encouraged by my colleagues to report any } \\
\text { medication safety concerns I may have. }\end{array}$ & 4.55 & 0.83 & & 0.73 & & & & & \\
\hline $\mathrm{B} 1(\mathrm{R})$ & $\begin{array}{l}\text { In this clinical area, it is difficult to discuss } \\
\text { medication errors. }\end{array}$ & 4.44 & 0.94 & & 0.38 & & & & & \\
\hline B2 & $\begin{array}{l}\text { Medication errors are managed and investigated } \\
\text { appropriately in this clinical area. }\end{array}$ & 4.53 & 0.85 & & 0.45 & & & & & \\
\hline B5 & $\begin{array}{l}\text { In this clinical area it is easy to learn from the } \\
\text { medication errors of others. }\end{array}$ & 4.16 & 0.96 & & 0.52 & & & & & \\
\hline 3. & Job satisfaction (JS) & & & & & & & & & \\
\hline $\mathrm{C} 1$ & I like my job. & 4.57 & 0.78 & & & 0.72 & & & & \\
\hline $\mathrm{C} 2$ & Working here is like being part of a large family. & 4.02 & 1.10 & & & 0.75 & & & & \\
\hline $\mathrm{C} 3$ & This is a good place to work. & 4.54 & 0.77 & & & 0.87 & & & & \\
\hline $\mathrm{C} 4$ & I am proud to work in this clinical area. & 4.66 & 0.70 & & & 0.77 & & & & \\
\hline $\mathrm{C} 5$ & Morale in this clinical area is high. & 3.87 & 1.16 & & & 0.73 & & & & \\
\hline 4. & Stress Recognition (SR) & & & & & & & & & \\
\hline C6 & $\begin{array}{l}\text { My medication safety performance is impaired if } \\
\text { my workload becomes excessive. }\end{array}$ & 3.68 & 1.31 & & & & 0.81 & & & \\
\hline $\mathrm{C} 7$ & $\begin{array}{l}\text { If I am tired, I am less effective at work dealing } \\
\text { with medications. }\end{array}$ & 3.79 & 1.23 & & & & 0.89 & & & \\
\hline $\mathrm{C} 8$ & $\begin{array}{l}\text { I am more likely to make medication errors in } \\
\text { tense and hostile situations. }\end{array}$ & 3.88 & 1.22 & & & & 0.71 & & & \\
\hline C9 & $\begin{array}{l}\text { Being tired impairs my performance during } \\
\text { emergency situations (e.g. emergency } \\
\text { resuscitation, seizure). }\end{array}$ & 3.41 & 1.40 & & & & 0.68 & & & \\
\hline 5. & Perceptions of management (PM) & & & & & & & & & \\
\hline D1 & $\begin{array}{l}\text { Management in this clinical area supports my } \\
\text { daily efforts with medication. }\end{array}$ & 4.09 & 1.02 & & & & & 0.68 & & \\
\hline D2 & $\begin{array}{l}\text { Management in this clinical area doesn't } \\
\text { knowingly compromise medication safety. }\end{array}$ & 4.41 & 0.92 & & & & & 0.51 & & \\
\hline
\end{tabular}


Table 1 continued

\begin{tabular}{|c|c|c|c|c|c|c|c|c|c|c|c|c|}
\hline \multirow{2}{*}{ Items } & & \multirow{2}{*}{$\begin{array}{l}\text { Mean } \\
\text { (5-point scale) }\end{array}$} & \multirow{2}{*}{$\mathrm{SD}$} & \multicolumn{9}{|c|}{ Factor loadings } \\
\hline & & & & TW & $\mathrm{SC}$ & JS & SR & PM & $\mathrm{WC}$ & $\mathrm{OL}$ & FCE & MS \\
\hline D3 & $\begin{array}{l}\text { Management in this clinical area is doing a good } \\
\text { job. }\end{array}$ & 4.17 & 1.02 & & & & & 0.70 & & & & \\
\hline D4 & $\begin{array}{l}\text { Problem staff are dealt with constructively by } \\
\text { management in this clinical area. }\end{array}$ & 3.72 & 1.20 & & & & & 0.70 & & & & \\
\hline D5 & $\begin{array}{l}\text { I get adequate, timely information about } \\
\text { medication safety from management in this } \\
\text { clinical area. }\end{array}$ & 4.09 & 0.99 & & & & & 0.64 & & & & \\
\hline $\mathrm{C} 13$ & $\begin{array}{l}\text { The levels of staffing in this clinical area are } \\
\text { sufficient to handle the number of patients. }\end{array}$ & 3.61 & 1.33 & & & & & 0.50 & & & & \\
\hline E1 & $\begin{array}{l}\text { Hospital management supports my daily efforts } \\
\text { with medication. }\end{array}$ & 3.85 & 1.08 & & & & & 0.72 & & & & \\
\hline E2 & $\begin{array}{l}\text { Hospital management doesn't knowingly } \\
\text { compromise medication safety. }\end{array}$ & 4.14 & 0.99 & & & & & 0.63 & & & & \\
\hline E3 & Hospital management is doing a good job. & 3.98 & 0.96 & & & & & 0.78 & & & & \\
\hline E4 & $\begin{array}{l}\text { Problem staff are dealt with constructively by } \\
\text { our hospital management. }\end{array}$ & 3.49 & 1.19 & & & & & 0.67 & & & & \\
\hline E5 & $\begin{array}{l}\text { I get adequate, timely information about } \\
\text { medication safety that might affect my work } \\
\text { from hospital management. }\end{array}$ & 4.05 & 0.95 & & & & & 0.70 & & & & \\
\hline 6. & Working Conditions (WC) & & & & & & & & & & & \\
\hline $\mathrm{C} 10$ & $\begin{array}{l}\text { This clinical area does a good job of training } \\
\text { new staff. }\end{array}$ & 4.18 & 0.99 & & & & & & 0.82 & & & \\
\hline C11 & $\begin{array}{l}\text { All the necessary information for diagnostic and } \\
\text { therapeutic decisions is routinely available to } \\
\text { me. }\end{array}$ & 4.25 & 0.87 & & & & & & 0.77 & & & \\
\hline $\mathrm{C} 12$ & $\begin{array}{l}\text { Trainees in my discipline are adequately } \\
\text { supervised. }\end{array}$ & 4.35 & 0.95 & & & & & & 0.69 & & & \\
\hline 7. & Organisational learning $(\mathrm{OL})$ & & & & & & & & & & & \\
\hline A11 & $\begin{array}{l}\text { In this clinical area staff are actively doing things } \\
\text { to improve medication safety. }\end{array}$ & 4.48 & 0.83 & & & & & & & 0.78 & & \\
\hline A12 & $\begin{array}{l}\text { In this clinical area errors in medication use have } \\
\text { led to positive changes. }\end{array}$ & 4.47 & 0.80 & & & & & & & 0.76 & & \\
\hline A13 & $\begin{array}{l}\text { In this clinical area, after changes are made to } \\
\text { improve medication safety, staff evaluate its } \\
\text { effectiveness. }\end{array}$ & 4.07 & 0.95 & & & & & & & 0.71 & & \\
\hline 8. & Feedback and communication about error (FCE) & & & & & & & & & & & \\
\hline B3 & $\begin{array}{l}\text { Clinical staff are informed about medication } \\
\text { errors that happen in this clinical area. }\end{array}$ & 4.29 & 0.98 & & & & & & & & 0.81 & \\
\hline B4 & $\begin{array}{l}\text { Clinical staff are given feedback about changes } \\
\text { put in place after a medication error occurs. }\end{array}$ & 4.14 & 1.00 & & & & & & & & 0.84 & \\
\hline B6 & $\begin{array}{l}\text { In this clinical area, we discuss ways to prevent } \\
\text { medication errors from happening again. }\end{array}$ & 4.28 & 0.99 & & & & & & & & 0.76 & \\
\hline 9. & Management support for patient safety (MS) & & & & & & & & & & & \\
\hline E6 & $\begin{array}{l}\text { Hospital management provides a work } \\
\text { environment that promotes medication safety. }\end{array}$ & 4.07 & 0.92 & & & & & & & & & 0.85 \\
\hline E7 & $\begin{array}{l}\text { The actions of hospital management show that } \\
\text { medication safety is a top priority. }\end{array}$ & 4.10 & 0.94 & & & & & & & & & 0.81 \\
\hline E8 (R) & $\begin{array}{l}\text { Hospital management seems interested in } \\
\text { medication safety only after a medication } \\
\text { incident happens. }\end{array}$ & 3.00 & 1.36 & & & & & & & & & 0.37 \\
\hline
\end{tabular}

